\title{
Importance of Cocaine- and Amphetamine-Regulated Transcript Peptide in the Central Nucleus of Amygdala in Anxiogenic Responses Induced by Ethanol Withdrawal
}

\author{
Manoj P Dandekar', Praful S Singru' ${ }^{2}$ Dadasaheb M Kokare', Ronald M Lechan ${ }^{2}$, Lars Thim ${ }^{3}$, \\ Jes Thorn Clausen ${ }^{4}$ and Nishikant K Subhedar*, \\ 'Department of Pharmaceutical Sciences, Rashtrasant Tukadoji Maharaj Nagpur University Campus, Nagpur, India; ${ }^{2}$ Division of Endocrinology, \\ Diabetes and Metabolism, Tufts-New England Medical Center, Boston, MA, USA; ${ }^{3}$ Department of Assay and Cell Technology, Novo Nordisk A/S, \\ Bagsvaerd, Denmark; ${ }^{4}$ Department of Protein Chemistry, Novo Nordisk A/S, Bagsvaerd, Denmark
}

\begin{abstract}
We studied the involvement of cocaine- and amphetamine-regulated transcript peptide (CART) in the central nucleus of amygdala (CeA), lateral bed nucleus of the stria terminalis (BNSTI) and nucleus accumbens shell (AcbSh) in generation of ethanol withdrawal symptoms, with particular focus on anxiety-like behavior using a social interaction test. Administration of CART (54-102) into the lateral ventricle (50 and $100 \mathrm{ng}$ ) and bilaterally in the CeA ( 10 and $20 \mathrm{ng}$ ) caused a significant reduction in social interaction, suggesting an anxiogenic action of the peptide. Chronic ethanol treatment for 15 days followed by withdrawal precipitated an anxiogenic response at $24 \mathrm{~h}$ that was attenuated by intracerebroventricular $(5 \mu \mid)$ and intra-CeA $(|\mu|)$ administration of antibodies against CART ( I:500 dilution). An immunocytochemistry protocol was employed to study the response of the endogenous CART system in the CeA following chronic ethanol withdrawal. At $\mathrm{O}$ h ethanol withdrawal, CART immunoreactivity was apparent in few fibers and the profile was similar to that in the pair-fed control rats. Twenty-four hours following ethanol withdrawal, a highly significant increase $(P<0.00 \mathrm{I})$ in CART immunoreactivity was noticed in the CeA, which returned to normal 48 and $72 \mathrm{~h}$ post-withdrawal. Similar doses of CART or CART antibody injected bilaterally into the BNSTI or AcbSh produced no response in the social interaction test. Furthermore, the CART immunoreactivity profile did not change at the post-withdrawal time points in each of these brain sites. We suggest that CART may mediate the early signs of anxiety-like behavior induced by ethanol withdrawal within the neuroanatomical framework of the CeA. Neuropsychopharmacology (2008) 33, I |27-I |36; doi:I0.1038/sj.npp. I30 I 5 I6; published online I8 July 2007
\end{abstract}

Keywords: cocaine-and amphetamine-regulated transcript peptide; ethanol; withdrawal anxiety; central nucleus of amygdala; social interaction test; immunocytochemistry

\section{INTRODUCTION}

A wealth of data suggests that cocaine- and amphetamineregulated transcript peptide (CART), a new member of the neuropeptide family, has neurotransmitter-like actions in the brain (Kuhar and Dall Vechia, 1999) and increases in regions of the brain in response to the psychostimulants, cocaine and amphetamine (Douglass et al, 1995). To date, several CART peptide fragments have been identified (Kuhar and Yoho, 1999; Thim et al, 1999). Among them, two biologically active fragments, CART 55-102 and 62-102, have been isolated and sequenced from the rat hypothalamus and pituitary (Gautvik et al, 1996; Kristensen et al, 1998; Thim et al, 1998, 1999; Bannon et al, 2001). Within the

*Correspondence: Professor NK Subhedar, Department of Pharmaceutical Sciences, Rashtrasant Tukadoji Maharaj Nagpur University Campus, Nagpur 440 033, India, Fax: +91 712 2549521, +91 712 2563356, E-mail: nksubhedar@hotmail.com

Received 16 February 2007; revised 12 June 2007; accepted I4 June 2007 brain, CART-expressing elements are particularly abundant in the nucleus accumbens (Acb), lateral bed nucleus of stria terminalis (BNSTl), arcuate nucleus (ARC), amygdala, hippocampus, midbrain raphe, locus coeruleus, and pituitary (Couceyro et al, 1997; Koylu et al, 1997, 1998; Elias et al, 1998; Vrang et al, 1999).

CART peptides are involved in the regulation of pain, arousal, startle response, regulation of calcium channels, and neuroendocrine hormone secretion (Bannon et al, 2001; Yermolaieva et al, 2001; Smith et al, 2004). A role of CART in the Acb in drug reward and reinforcement has also been suggested (Koylu et al, 1998; Smith et al, 1999). Salinas et al (2006) have recently observed that CART peptide and its mRNA are expressed in the Acb in response to acute ethanol administration, suggesting that CART may be an endogenous mediator of the rewarding and reinforcing properties of ethanol. In support of this concept is the recent identification of a polymorphism in intron 1 of the CART gene that is associated with alcoholism in the Korean male population (Jung et al, 2004). CART also plays an important role in anxiety-like behavior and stress-related 
responses (Chaki et al, 2003; Stanek, 2006), and dosedependently enhances anxiety-like behavior in the elevated plus maze (EPM) test in both rats (Kask et al, 2000) and mice (Asakawa et al, 2001).

Regions of the extended amygdala that include the central nucleus of amygdala (CeA), BNSTl and nucleus accumbens shell (AcbSh), play a key role in drug abuse and dependence (Koob, 2003b), mediation of alcohol addictive processes (Koob, 2003b; Pandey, 2004) and physiological responses associated with anxiety-like behavior (LeDoux et al, 1988; Walker and Davis, 1997). The amygdala also plays an important role in processing anxiety-related signals induced by ethanol withdrawal and exhibits changes in the neurotransmitter profile during ethanol dependence and withdrawal (Merlo Pich et al, 1995; Koob, 2003a; Zhang and Pandey, 2003). Lesions of the CeA, but not basolateral amygdala, decrease anxiety-like behaviors and voluntary ethanol consumption in rats (Moller et al, 1997). Chronic intake of ethanol modifies synaptic and intracellular signaling in the amygdala (Pandey et al, 2003), whereas acute ethanol administration stimulates c-fos expression in CeA (Criado and Morales, 2000). CART-containing fibers have been demonstrated in the $\mathrm{CeA}$ and its role in drug reward and reinforcement has been proposed (Koylu et al, 1998). However, the importance of CART in ethanol withdrawalinduced anxiety-like behavior has not been explored.

In the present study, we investigated the role of CART in the extended amygdala in the regulation of anxiety-like behavior following the chronic ethanol treatment and withdrawal in rats. We hypothesized that through actions in the extended amygdala, CART may be involved in ethanol withdrawal-induced anxiety-like behavior. Herein, we administered CART intracerebroventricularly (icv), and also directly into the CeA, BNSTl or AcbSh of the normal rats, and evaluated the anxiety-like behavior by employing a social interaction test. Using the same behavioral paradigm, ethanol withdrawal-induced anxiety-like behavior was tested in rats treated with antibodies against CART given by the icv and intra-CeA, -BNSTl or -AcbSh routes. Furthermore, the effect of chronic ethanol treatment and/ or withdrawal on the endogenous CART-containing system in CeA, BNSTl or AcbSh was investigated using immunocytochemistry coupled with morphometric analysis.

\section{MATERIALS AND METHODS}

\section{Animals}

Adult, male, Sprague-Dawley rats (230-250 g) were grouphoused, but after icv and intra-nuclei (CeA, BNSTl or AcbSh) cannulation, they were housed individually. All animals had free access to food (Lipton, India) and drinking water except during the test period or some special experimental protocols. They were maintained on a $12 \mathrm{~h}$ dark/light cycle, in controlled temperature $\left(25 \pm 2{ }^{\circ} \mathrm{C}\right)$ and relative humidity (50-70\%). The experimental procedures were approved by the Institutional Animal Ethical Committee.

\section{Intracerebral Cannulations}

The detailed procedure of cannulation, drug administration, and post-surgical care has been described (Kokare et al,
2005, 2006). A stainless steel guide cannula (C316G/Spc; Plastics One, Roanoke, VA) was implanted into the right lateral cerebral ventricle using the stereotaxic coordinates, $-0.8 \mathrm{~mm}$ posterior, $+1.3 \mathrm{~mm}$ lateral to midline, and $3.5 \mathrm{~mm}$ ventral with respect to bregma (Paxinos and Watson, 1998). Similarly, the cannulae were implanted bilaterally in the CeA $(-2.4 \mathrm{~mm}$ posterior, $\pm 4.0 \mathrm{~mm}$ lateral to midline and $8.0 \mathrm{~mm}$ ventral), BNSTl $(-0.3 \mathrm{~mm}$ posterior, $\pm 1.6 \mathrm{~mm}$ lateral to midline and $6.0 \mathrm{~mm}$ ventral) or AcbSh $(+1.7 \mathrm{~mm}$ anterior, $\pm 0.8 \mathrm{~mm}$ lateral to midline and $6.5 \mathrm{~mm}$ ventral) in other groups. The animals were allowed a recovery period of 7 days and those with any neurological/motor deficits were excluded from the study.

\section{Ethanol Treatment}

The rats were given ethanol in a liquid diet for 15 days according to the previously described protocol (Pandey et al, 1999; Kokare et al, 2006). Briefly, rats were given a nutritionally balanced control liquid diet (Novartis, India) for 2 days for adaptation to the novel food. From day 3 onwards, ethanol was gradually introduced into the liquid diet starting with $4.5 \%(\mathrm{v} / \mathrm{v})$ ethanol on the first day, $7.5 \%$ $(\mathrm{v} / \mathrm{v})$ ethanol on the second day and $9 \%(\mathrm{v} / \mathrm{v})$ ethanol thereafter for 15 days (ethanol-fed group, $n=27$ ). The rest of the animals continued on the nutritionally balanced control liquid diet (pair-fed control group, $n=23$ ). A fresh aliquot of ethanol diet or control liquid diet $(100 \mathrm{ml} / \mathrm{rat})$ was provided each morning. After 15 days, all the animals were placed on an ethanol-free, nutritionally balanced diet and killed at $0,24,48$, and $72 \mathrm{~h}$ post-withdrawal, and their brains processed for CART immunolabeling.

\section{Icv, Intra-CeA, -BNSTl and -AcbSh Administration of CART and CART Antibody}

The methods of icv and nuclei-specific injections and preparation of artificial CSF (aCSF) have already been described (Kokare et al, 2005, 2006). Cannulated rats were randomly allocated to different groups ( $n=8$ in each). All injections were performed between 0900 and $1200 \mathrm{~h}$ in a randomized way and rats, once used, were not re-employed. CART (54-102) was dissolved in aCSF and injected into the right lateral ventricle or bilaterally into the CeA, BNSTl or AcbSh. Various agents like aCSF $(5 \mu \mathrm{l} / \mathrm{rat}$, icv; $n=7$, and $1 \mu \mathrm{l}$ each side for intra-CeA, -BNSTl or -AcbSh; $n=6, n=7$ or $n=7$ respectively) and CART (25-100 ng/rat, icv; $n=8$ per group and 2-20 ng/rat for intra-CeA, -BNSTl or -AcbSh; $n=6, n=8$ or $n=6$ per group respectively) were given as single injection and subjected to the social interaction test (see below) following an interval of $30 \mathrm{~min}$.

To study the effect of immunoneutralization of endogenous CART on social interaction following ethanol-withdrawal, cannulae were implanted either into the lateral ventricle or bilaterally into the $\mathrm{CeA}$, BNSTl or AcbSh as described above. Twenty-two hours following withdrawal, rats were injected with (i) aCSF $(5 \mu \mathrm{l} / \mathrm{rat}$, icv; $n=8$ or $1 \mu \mathrm{l}$ each side for intra-CeA, -BNSTl or -AcbSh; $n=6$ in each group), (ii) non-immune serum (1:500 dilution, $5 \mu \mathrm{l} / \mathrm{rat}$, icv; $n=7$ or $1 \mu \mathrm{l}$ each side for intra-CeA, -BNSTl or -AcbSh; $n=7$ in each group) or (iii) antibody against CART (1:500 dilution, $5 \mu \mathrm{l} / \mathrm{rat}$, icv; $n=6$ or $1 \mu \mathrm{l}$ each side for intra-CeA; 
$n=8$, -BNSTl; $n=8$ or -AcbSh; $n=6$ ). Two hours after the injection, animals were subjected to social interaction test (see below). Earlier studies used the antibodies for immunoneutralization in similar timeframe and dilution range (Scruggs et al, 2003). The responses were scored by a trained observer blind to various treatment conditions. In all experiments, CART and CART antibody-treated groups were run in parallel with their respective control group. The placement of the cannula for icv injection was tested for accuracy by injecting dilute India ink and post-mortem examination of the distribution of ink in the ventricles (Kokare et al, 2006) and the 52 animals with correct placement were used for statistical analysis.

Following intra-CeA, -BNSTl and -AcbSh injections, the brains (168 rats) were removed, sectioned, stained with cresyl violet, and the position of the tip of each injection site was determined (see Supplementary Figure S1). Only animals with correct cannula placements ( 45 rats for intra$\mathrm{CeA}, 52$ rats for intra-BNSTl, and 44 rats for intra-Acb) were used for statistical analysis.

\section{Social Interaction Test for Anxiety}

The social interaction test (File and Hyde, 1978) was performed according to Gonzalez et al (1998) with slight modification. Two rats naïve to the test were taken. The index rat was implanted with cannula, while the untreated dummy partner was taken from separate cage and placed into the center of a test box $(60 \times 60 \mathrm{~cm}$ open field with 16 $15 \times 15 \mathrm{~cm}$ squares marked on the floor) simultaneously for a 10-min period. Reduced social interaction time reflected the increased anxiety-like behavior. Locomotor activity was measured as the number of squares entered during the interaction session. The time that the index rat socially interacted, which includes genital investigation, sniffing, following, grooming, kicking, crawling under or over the partner, and touching or nearly touching their faces with the untreated dummy partner was visually measured. The occurrence of at least one of the behaviors was recorded and the data are shown in Figures 1-5.

\section{Immunocytochemistry}

Brains of ethanol-treated as well as pair-fed rats collected at the $0,24,48$, and $72 \mathrm{~h}$ post-withdrawal time points were processed for immunocytochemical labeling. Rats were anesthetized (pentobarbital, $50 \mathrm{mg} / \mathrm{kg}$, intraperitoneally), perfused transcardially with heparinized phosphatebuffered saline (PBS; $\mathrm{pH}$ 7.4) for $30 \mathrm{~s}$ followed by $4 \%$ paraformaldehyde in $0.1 \mathrm{M}$ phosphate buffer ( $\mathrm{pH}$ 7.4) for 10-15 min. The brains were post-fixed in the same fixative overnight, cryoprotected in $30 \%$ sucrose solution, embedded, and serially sectioned on a cryostat (Leica) at $20 \mu \mathrm{m}$ thickness in the coronal plane and collected in PBS. Sections were processed for CART immunolabeling using the streptavidin-biotin-peroxidase method described earlier (Singru et al, 2007). Briefly, sections were incubated in mouse monoclonal primary antibodies against CART (54-102) diluted in $1 \%$ bovine serum albumin (Sigma) containing $0.3 \%$ Triton $\mathrm{X}-100$ and $0.09 \%$ sodium azide at $1: 5000$ dilution for 2 days at $4^{\circ} \mathrm{C}$. After rinsing in PBS, the sections were incubated in biotinylated-IgG followed by
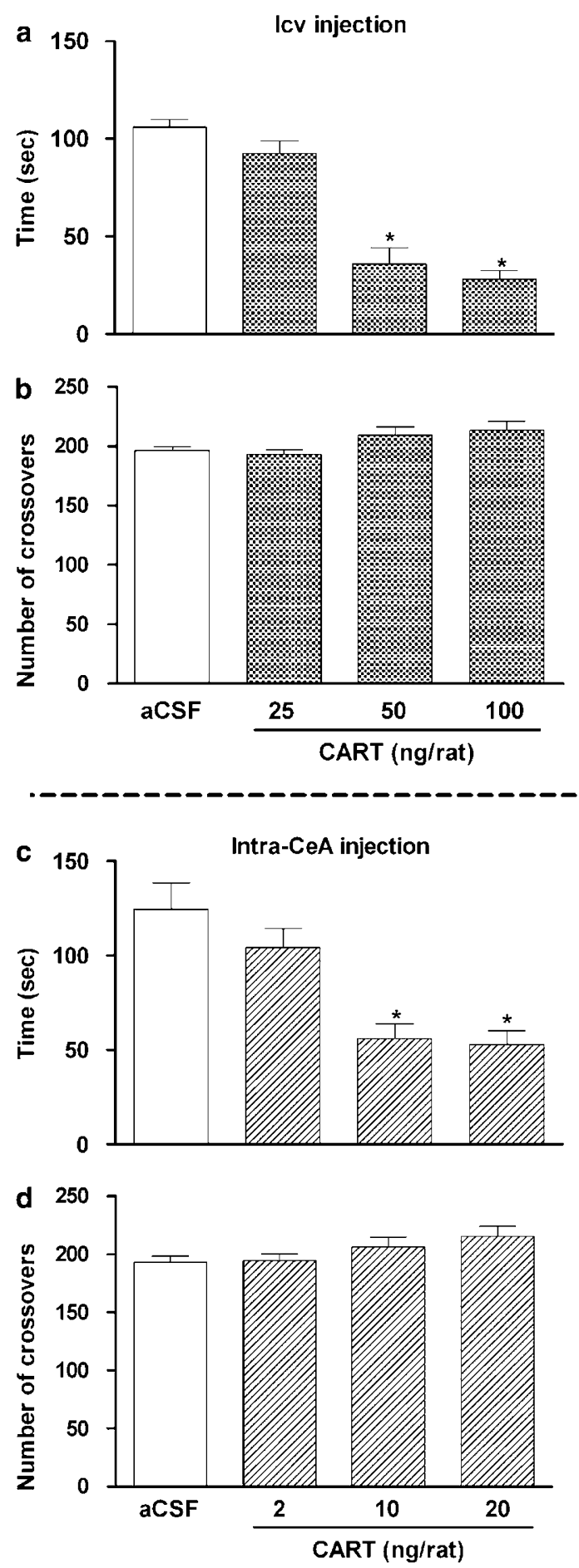

Figure I Effect of different doses of CART (54-102) administered via icv or intra-CeA route on social interaction time (a and $c$ ) and number of crossovers ( $b$ and $d$ ) in the social interaction test in normal rats. The data were analyzed by one-way ANOVA with repeated measures on drug treatments followed by post hoc Dunnett's test. Each bar is the mean \pm SEM for $6-8$ rats. $* P<0.01$ vs aCSF-treated group.

$\mathrm{ABC}$ (Vector) and the immunoreaction product was developed in diaminobenzedine/ $\mathrm{H}_{2} \mathrm{O}_{2}$ in Tris buffer. Sections were dehydrated, cleared in xylene, and mounted with DPX. To ensure reliable comparisons among different groups and maintain stringency in tissue preparation and 

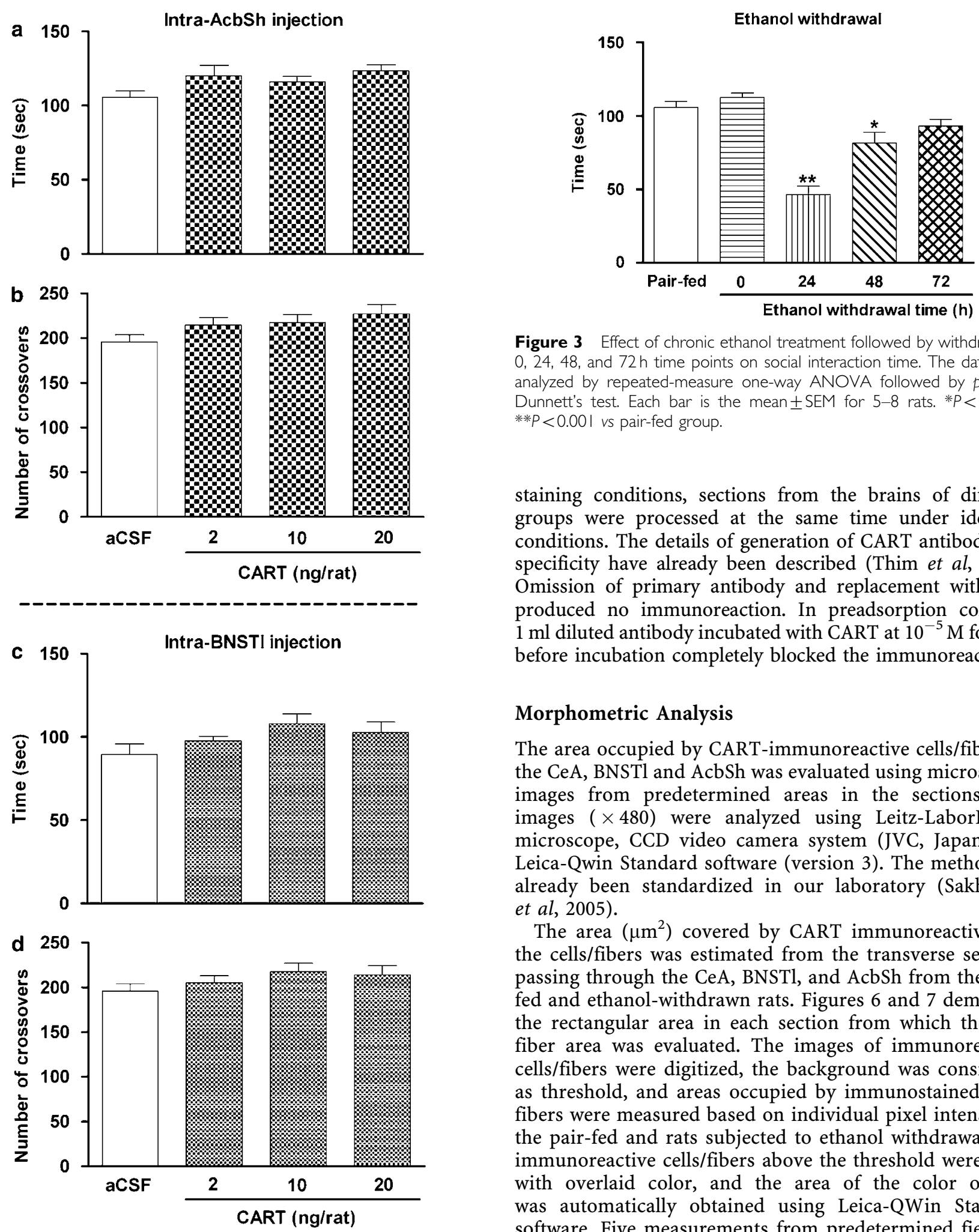

Figure 2 Effect of different doses of CART (54-102) administered bilaterally via intra-AcbSh or -BNSTI route on social interaction time (a and c) and number of crossovers (b and d) in the social interaction test in normal rats. The data were analyzed by one-way ANOVA with repeated measures on drug treatments followed by post hoc Dunnett's test. Each bar is the mean \pm SEM for 6-8 rats. No significant difference was found at the different doses of CART administered $(P>0.05)$.

staining conditions, sections from the brains of different groups were processed at the same time under identical conditions. The details of generation of CART antibody and specificity have already been described (Thim et al, 1998). Omission of primary antibody and replacement with BSA produced no immunoreaction. In preadsorption controls, $1 \mathrm{ml}$ diluted antibody incubated with CART at $10^{-5} \mathrm{M}$ for $24 \mathrm{~h}$ before incubation completely blocked the immunoreaction.

\section{Morphometric Analysis}

The area occupied by CART-immunoreactive cells/fibers in the CeA, BNSTl and AcbSh was evaluated using microscopic images from predetermined areas in the sections. The images $(\times 480)$ were analyzed using Leitz-LaborLux $S$ microscope, CCD video camera system (JVC, Japan) and Leica-Qwin Standard software (version 3). The method has already been standardized in our laboratory (Sakharkar et al, 2005).

The area $\left(\mu \mathrm{m}^{2}\right)$ covered by CART immunoreactivity in the cells/fibers was estimated from the transverse sections passing through the CeA, BNSTl, and AcbSh from the pairfed and ethanol-withdrawn rats. Figures 6 and 7 demarcate the rectangular area in each section from which the cell/ fiber area was evaluated. The images of immunoreactive cells/fibers were digitized, the background was considered as threshold, and areas occupied by immunostained cells/ fibers were measured based on individual pixel intensity in the pair-fed and rats subjected to ethanol withdrawal. The immunoreactive cells/fibers above the threshold were filled with overlaid color, and the area of the color overlay was automatically obtained using Leica-QWin Standard software. Five measurements from predetermined fields of the CeA, BNSTl and AcbSh on both sides of each brain were taken. The data from all the animals in each group were pooled separately and the mean \pm SEM calculated.

\section{Statistical Analyses}

For the dose-dependent study of CART in the social interaction test, statistical significance was determined by 

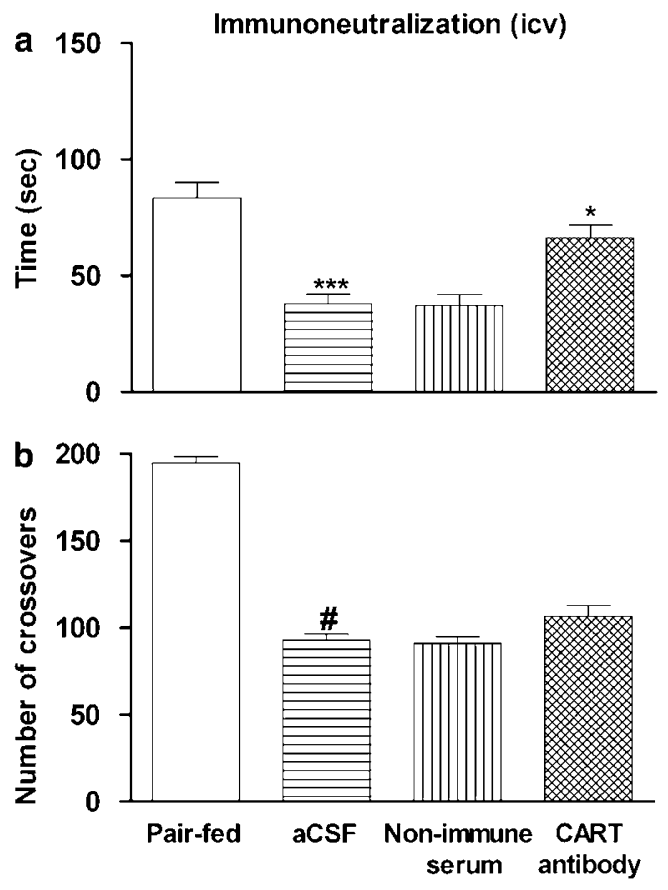

Ethanol withdrawal
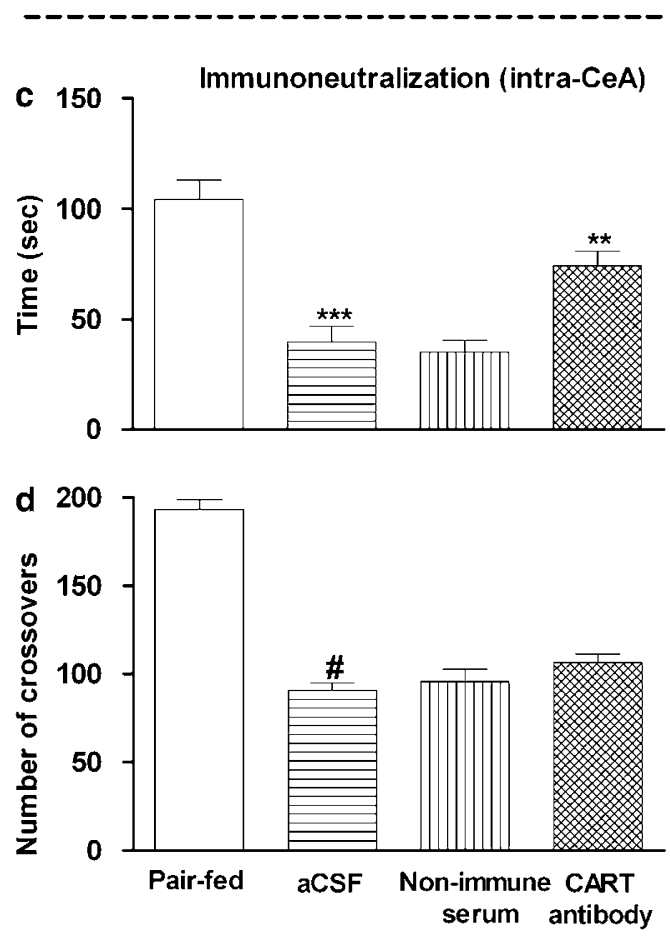

Ethanol withdrawal

Figure 4 Effect of aCSF, non-immune serum, and CART antibody administered by icv or intra-CeA route on the social interaction time (a and c) and number of crossovers (b and d) in pair-fed and/or $24 \mathrm{~h}$ ethanolwithdrawal rats. The agents were administered $2 \mathrm{~h}$ before the test. The data were analyzed by unpaired $t$-test or one-way repeated measures ANOVA followed by Student-Newman-Keuls test. Each bar is the mean \pm SEM for $6-8$ rats. ${ }^{*} * * P<0.0002$ and ${ }^{\#} P<0.000$ I vs pair-fed group; $* P<0.01$ and ${ }^{*} * P<0.001$ vs non-immune serum-treated group following $24 \mathrm{~h}$ ethanol withdrawal.
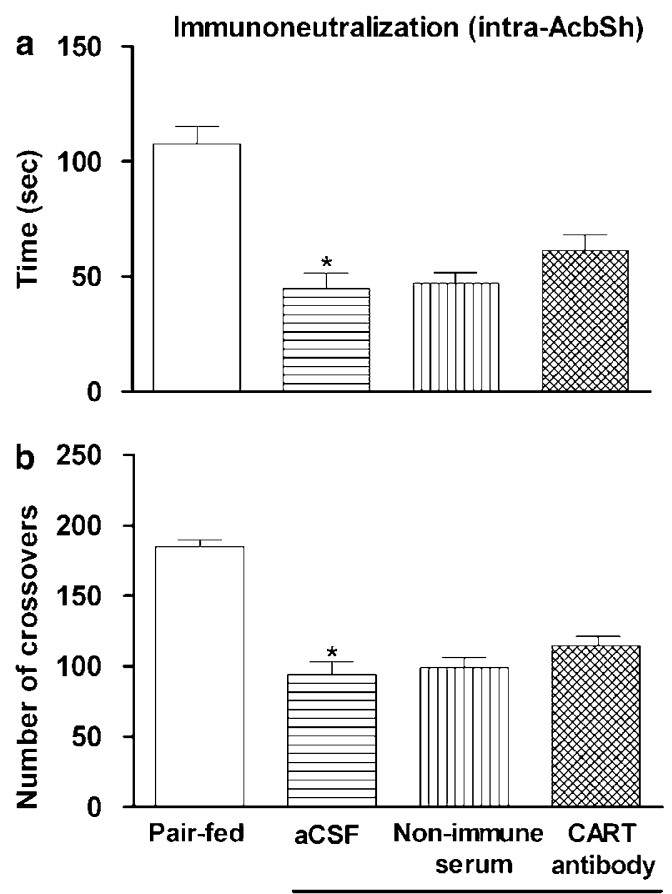

Ethanol withdrawal
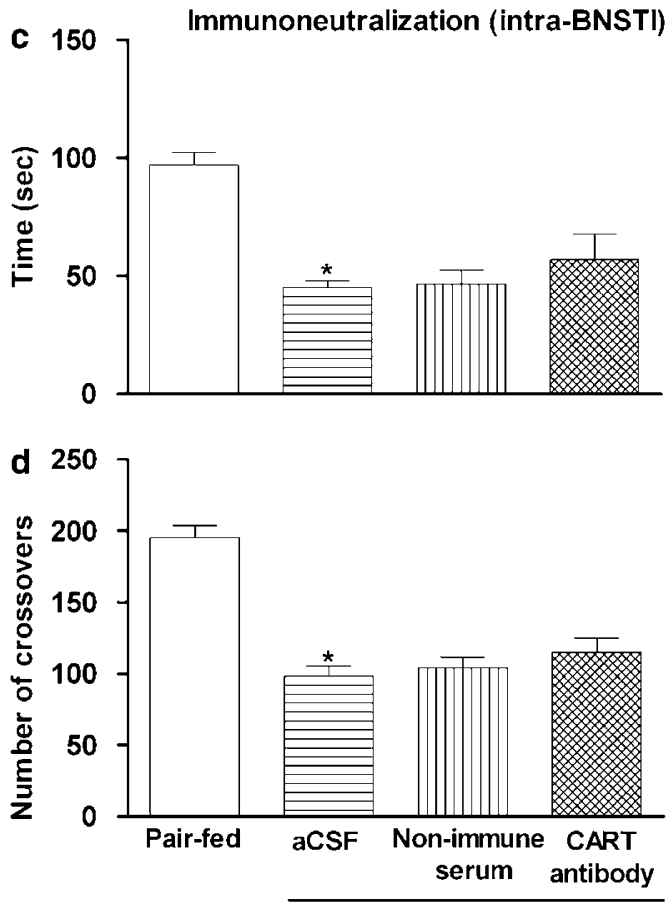

Ethanol withdrawal

Figure 5 Effect of aCSF, non-immune serum and CART antibody administered by intra-AcbSh or -BNSTI route on the social interaction time ( $a$ and $c$ ) and number of crossovers ( $b$ and $d$ ) in pair-fed and/or $24 \mathrm{~h}$ ethanol-withdrawal rats. The agents were administered $2 \mathrm{~h}$ before the test. The data were analyzed by unpaired $t$-test or one-way repeated measures ANOVA followed by Student-Newman-Keuls test. Each bar is the mean \pm SEM for $6-8$ rats. ${ }^{*} P<0.0001$ vs pair-fed rats. No significant difference was found in the non-immune serum-, and CART antibodytreated groups following $24 \mathrm{~h}$ ethanol withdrawal $(P>0.05)$. 

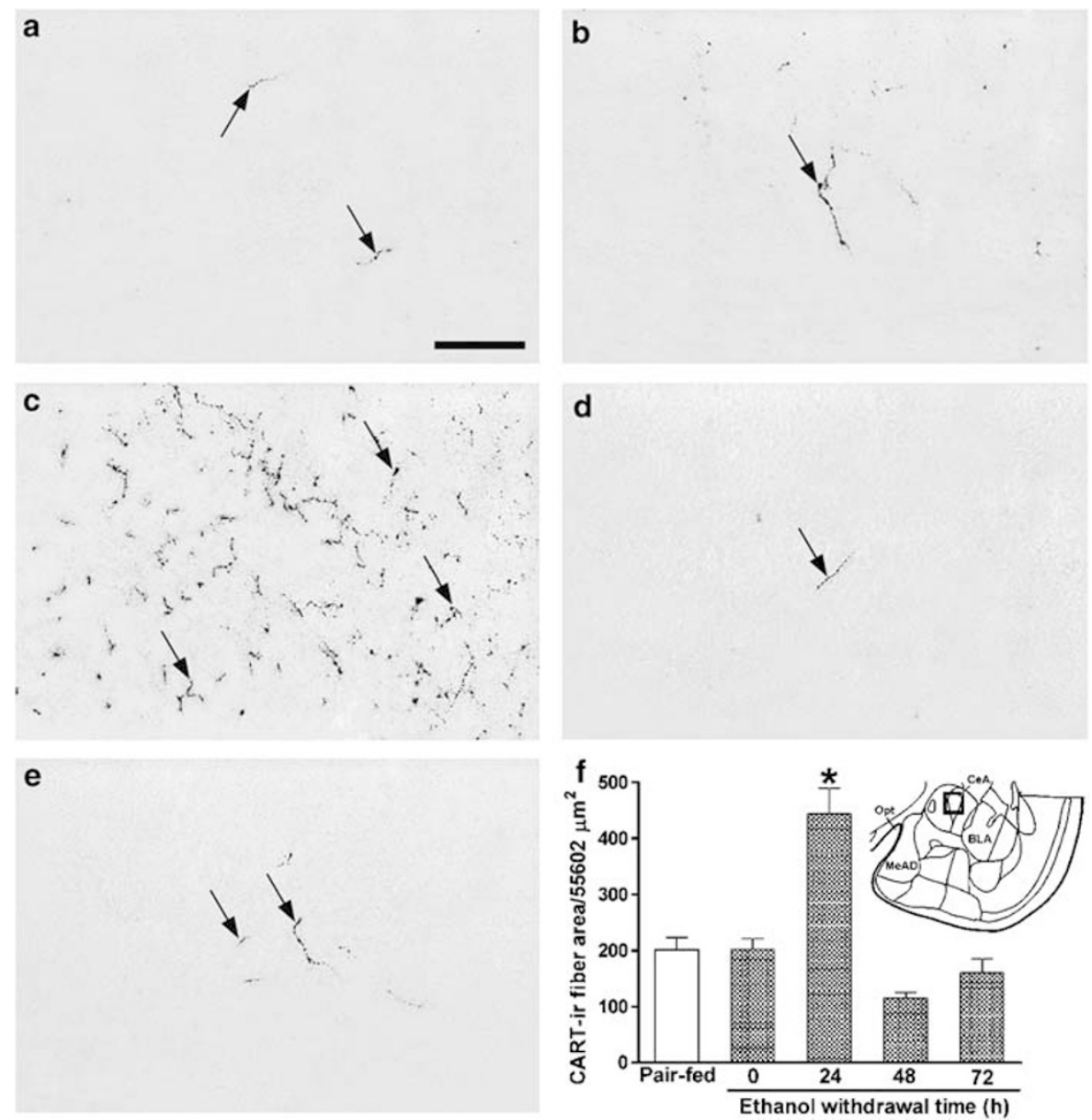

Figure 6 Photomicrographs showing CART-immunoreactive (CART-ir) fibers (arrows) in the CeA of pair-fed (a) and ethanol-withdrawn rats at $0 \mathrm{~h}$ (b), $24 \mathrm{~h} \mathrm{(c),48} \mathrm{h} \mathrm{(d),} \mathrm{and} 72 \mathrm{~h}$ (e). No significant difference in the CART immunoreactivity is seen in the CeA of pair-fed (a) and $0 \mathrm{~h}$ (b) ethanol-withdrawn rats. As compared to these animals, a dramatic increase in CART immunoreactivity is seen $24 \mathrm{~h}$ (c) following ethanol withdrawal. However, the CART immunoreactivity is considerably reduced in $48 \mathrm{~h}$ (d) and $72 \mathrm{~h}$ (e) ethanol-withdrawn animals; the immunoreactivity is comparable to that in the pair-fed animals. Diagram ( $f$, represents the semiquantitative morphometric analysis of CART immunoreactivity in the CeA of pair-fed and ethanol-withdrawn animals at different time points. The outline of the transverse section through the brain (coordinates: bregma $-2.56 \mathrm{~mm}$, Paxinos and Watson, 1998) indicates the region of the $\mathrm{CeA}$ (square not to scale) from which the measurements were collated. BLA, lateral part of basolateral amygdaloid nucleus; MeAD, anterodorsal part of medial amygdaloid nucleus; opt, optic tract. $* P<0.00$ I vs pair-fed group. Scale bar $=50 \mu \mathrm{m}$.
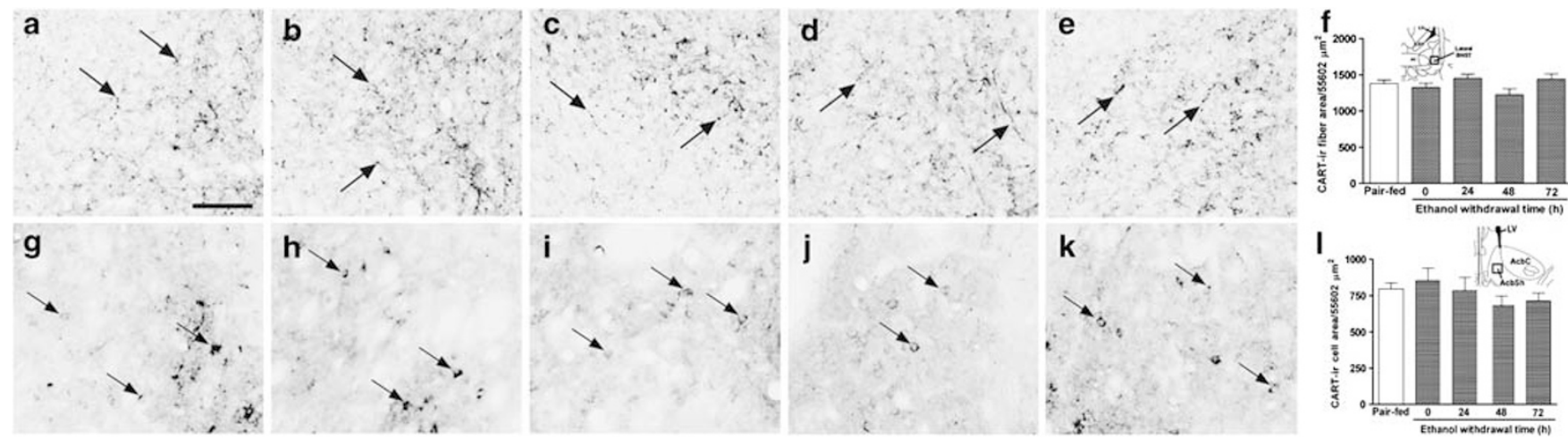

Figure 7 Photomicrographs showing CART-immunoreactive (CART-ir) fibers (arrows) in the BNSTI and CART-ir cells (arrows) in the AcbSh of pair-fed $(a, g)$ and ethanol-withdrawn rats at $\mathrm{O} \mathrm{h}(\mathrm{b}, \mathrm{h}), 24 \mathrm{~h}(\mathrm{c}, \mathrm{i}), 48 \mathrm{~h}(\mathrm{~d}, \mathrm{j})$, and $72 \mathrm{~h}(\mathrm{e}, \mathrm{k})$. CART immunoreactivity profile is similar in the brain sections of the pairfed $(a, g)$ and the rats at different time points post-ethanol withdrawal (b-e, h- $k, P>0.05)$. Diagrams $f$ and I represents the semiquantitative morphometric analysis of CART immunoreactivity in the BNSTI and AcbSh of pair-fed and ethanol-withdrawn animals at different time points. The outlines of the transverse sections through brain indicate the regions of the BNSTI and AcbSh at the coordinates -0.30 and $+1.70 \mathrm{~mm}$ with reference to bregma respectively (Paxinos and Watson, 1998) from which the measurements were collated (square not to scale). ac, anterior commissure; AcbC, nucleus accumbens core; LSV, ventral part of the lateral septal nucleus; LV, lateral ventricle. Scale bar $=50 \mu \mathrm{m}$. 
one-way analysis of variance (ANOVA) with repeated measures on drug treatments followed by post hoc Dunnett's test. The results of ethanol-withdrawn rats at different time points were also analyzed by one-way ANOVA followed by Dunnett's test. The data obtained from ethanol-withdrawn and pair-fed rats were compared with the unpaired $t$-test. The data from immunoneutralization and morphometric studies were analyzed with one-way repeated measures ANOVA, and individual means were compared by the post hoc Student-Newman-Keuls test. Differences were considered significant at $P<0.05$.

\section{RESULTS}

\section{Effect of CART in the Social Interaction Test}

Control rats normally engaged in $110 \mathrm{~s}$ of social interaction during the 10-min test period. However, CART, at the dose of $25-100 \mathrm{ng} / \mathrm{rat}$ by the icv route, significantly and dosedependently reduced the time spent in the social interaction $(\mathrm{F}(3,30)=73.813 ; P<0.0001)$, as compared to aCSF-treated rats (Figure 1a). Similarly, at the dose of $2-20 \mathrm{ng} / \mathrm{rat}$ by intra-CeA route, the time spent in the social interaction was significantly and dose-dependently reduced $(\mathrm{F}(3,26)=$ 12.337; $P<0.0001)$ as compared to that in the aCSF-treated rats (Figure 1c). On the other hand, CART at the dose of $2-20 \mathrm{ng} / \mathrm{rat}$ by intra-BNSTl or -AcbSh route, did not influence the time spent in the social interaction $(\mathrm{F}(3,24)=$ $2.111 ; P>0.05$ or $\mathrm{F}(3,30)=2.103 ; P>0.05$ respectively) as compared to that in the aCSF-treated rats (Figure 2a and c). None of the above treatments caused any effect on the number of line crossings (Figures $1 b, d$ and $2 b, d$ ) excluding effects on locomotor activity.

\section{Effect of Ethanol Withdrawal in the Social Interaction Test}

Chronic treatment of ethanol for 15 days $(0 \mathrm{~h}$ ethanol withdrawal) did not influence social interaction time compared to the pair-fed control rats $(P>0.05$, Figure 3$)$. However, ethanol-withdrawn rats at 24 and $48 \mathrm{~h}$ time points display a significant decrease $(P<0.001$ and $P<0.05$ respectively, Figure 3 ) in social interaction time as compared to pair-fed controls. The ethanol-withdrawn rats at $72 \mathrm{~h}$ showed slight augmentation in the social interaction time as compared to the $48 \mathrm{~h}$ ethanol-withdrawn rats, although the change was not significant $(P>0.05$, Figure 3$)$.

\section{Effect of Immunoneutralization of CART $24 \mathrm{~h}$ Following Ethanol Withdrawal in the Social Interaction Test}

During the 10 min social interaction test period, ethanolwithdrawn rats displayed the behavior for 35-40 s, while the corresponding pair-fed control rats sustained interaction for approximately $95 \mathrm{~s}$ and the differences were found to be highly significant (compared with unpaired $t$-test, $P<0.0002$, Figure $4 \mathrm{a}$ and $\mathrm{c}$ ). Ethanol withdrawal also reduced locomotor activity (Knapp et al, 2004; Kokare et al, 2006) as reflected by the lower number of crossovers during the social interaction test (compared with unpaired $t$-test, $P<0.0001$, Figures $4 \mathrm{~b}, \mathrm{~d}$ and $5 \mathrm{~b}, \mathrm{~d})$. Icv $(1: 500$ dilution, $5 \mu \mathrm{l} / \mathrm{rat})$ and intra-CeA (1:500 dilution, $1 \mu \mathrm{l}$ each side) injection of CART antibody resulted in significant reversal of ethanol withdrawal reduction in the time spent in the social interaction $(\mathrm{F}(2,20)=17.340 ; P<0.0001$ and $\mathrm{F}(2,20)=16.091 ; P<0.0001$ respectively), as compared to non-immune serum-treated rats (Figure $4 \mathrm{a}$ and $\mathrm{c}$ ). However, the intra-AcbSh or -BNSTl (1:500 dilution, $1 \mu$ leach side) injection of CART antibody did not produce changes in the social interaction time $(\mathrm{F}(2,20)=2.055 ; P=0.153$ or $\mathrm{F}(2,18)=0.729 ; P=0.498$ respectively) as compared to non-immune serum-treated rats (Figure $5 \mathrm{a}$ and $\mathrm{c}$ ). On the other hand, non-immune serum or CART antibody administered via icv (Figure 4b, $\mathrm{F}(2,20)=3.354$; $P=0.057$ ) or directly into the CeA (Figure $4 \mathrm{~d}, \mathrm{~F}(2,20)=$ 2.136; $P=0.147$ ), AcbSh (Figure 5b, $\mathrm{F}(2,20)=2.054$; $P=0.157$ ) or BNSTl (Figure 5d, $\mathrm{F}(2,18)=1.042$; $P=0.376)$ did not affect the reduced number of crossovers observed in the ethanol-withdrawn animals.

\section{Effect of Ethanol Treatment and Withdrawal on CART Immunoreactivity; the Central Nucleus of Amygdala}

Immunocytochemical application of antibodies against CART revealed few, weakly CART-immunoreactive fibers in the CeA of pair-fed control rats (Figure 6a) as well as in rats treated for 15 days with ethanol, and the difference was found not significant $(P>0.05$, Figure $6 \mathrm{~b})$. However, there was a dramatic increase in CART-immunoreactive fibers in the CeA $24 \mathrm{~h}$ following ethanol withdrawal $(P<0.001$, Figure $6 \mathrm{c}$ ) as compared to the pair-fed control animals, as well as animals treated for 15 days with ethanol. Considerable reduction $(P<0.001)$ in CART immunoreactivity was noticed in the $\mathrm{CeA}$ at $48 \mathrm{~h}$ following ethanol withdrawal (Figure $6 \mathrm{~d}$ ) as compared to $24 \mathrm{~h}$ of ethanol withdrawal. The $\mathrm{CeA}$ of $72 \mathrm{~h}$ ethanol-withdrawn rats showed slight augmentation in the immunoreactivity as compared to the $48 \mathrm{~h}$ ethanol-withdrawn rats (Figure $6 \mathrm{~d}$ and e), although the change was not significant $(P>0.05)$. The area covered by the immunoreactive fibers in the $72 \mathrm{~h}$ ethanol-withdrawn rats was similar to that in the pair-fed rats (Figure $6 \mathrm{f}$ ).

\section{The Lateral Bed Nucleus of Stria Terminalis and Nucleus Accumbens Shell}

Although the BNSTl showed several CART-containing fibers, no cells were detected. Chronic ethanol treatment for 15 days and withdrawal at $0,24,48$, and $72 \mathrm{~h}$ time points did not influence the CART-immunoreactive profile in the BNSTl $(P>0.05$, Figure 7a-f). Some CART-immunoreactive cells were seen in AcbSh area of control rats (Figure 7g). No change in CART immunoreactivity was noticed following ethanol withdrawal at different time points $(P>0.05$, Figure $7 \mathrm{~h}-1)$.

\section{DISCUSSION}

Several studies have suggested an important role of CART in anxiety-like behavior (Kask et al, 2000; Asakawa et al, 2001; Chaki et al, 2003). Administration of CART (89-103) icv to rats results in a decreased ratio of open/total arm entries and reduces time spent in open part of the maze, thus suggesting increased anxiety-like behavior (Kask et al, 2000). Using EPM as well as social interaction tests 
as behavioral paradigms, Chaki et al (2003) reported anxiogenic-like activity in mice following the icv administration of CART (55-102) in the dose range of $0.1-0.3 \mu \mathrm{g}$. Recently, the role of the CART in the modulation of anxiogenic-like effects has been reviewed (Stanek, 2006). The present results confirm and extend these findings. Administration of 50 and $100 \mathrm{ng}$ CART (54-102) to normal rats by the icv route produced significant anxiety-like behavior in the social interaction test. The peptide was also given at lower doses ( 10 and $20 \mathrm{ng} / \mathrm{rat}$ ) directly into the amygdala because this is believed to be the locus for generation of anxiety-like behavior (Adolphs et al, 1994; Kokare et al, 2005), and produced a similar response. The data suggest that $\mathrm{CeA}$ might be the site of anxiogenic-like action of CART. This interpretation is fully in agreement with immunocytochemistry data demonstrating that the number of CART-immunoreactive fibers in the CeA increased many fold at $24 \mathrm{~h}$ post-ethanol withdrawal when the anxiety-like behavior was at its peak. All the above treatments did not influence locomotor activity, and therefore effects observed in the social interaction test cannot be ascribed to alteration in locomotion.

CART is known to produce anxiety-like behavior (Kask et al, 2000; Chaki et al, 2003), which is also a cardinal sign of ethanol withdrawal, and therefore anxiety-like behavior was selected as a behavioral end point for evaluation. Results following administration of the antibodies against CART to the ethanol-withdrawn rats, icv as well as directly into the $\mathrm{CeA}$, also suggest an anxiogenic role for CART. Treatment with CART antibodies at $22 \mathrm{~h}$ post-ethanol withdrawal reversed the peak anxiety-like behavior observed at $24 \mathrm{~h}$ following ethanol withdrawal. A period of $24 \mathrm{~h}$ was selected because peak anxiety-like behavior was reported at this time point in ethanol withdrawal studies following chronic treatment (Pandey et al, 1999). While, ethanol-withdrawn animals show reduction in the locomotor activity, which was in agreement with the previous studies (Knapp et al, 2004; Kokare et al, 2006), injection of CART antibody did not affect the locomotor counts. Thus, reversal of anxietylike behavior in $24 \mathrm{~h}$ ethanol-withdrawn animals may not be related to the locomotion component.

In the present study, chronic ethanol treatment for 15 days did not result in any change in CART immunoreactivity in the $\mathrm{CeA}$ as compared to that in the pair-fed animals. The significance of this observation is not known. While icv as well as intra-CeA injection of CART produced anxiety-like behavior, ethanol withdrawal-generated anxiety-like behavior was attenuated by immunoneutralization of endogenous CART. These data suggest that CART produces its anxiogenic influence via its action in the CeA. This concept is further supported by the direct correlation between the population of CART-immunoreactive fiber in the CeA post-withdrawal at 24,48 , and $72 \mathrm{~h}$ with the degree of anxiety-like behavior as revealed in the social interaction test. The fiber population was maximum at $24 \mathrm{~h}$ post-withdrawal when the anxiety-like behavior was at its peak. We suggest, therefore, that increased synthesis as well as release of CART at this time point may be responsible for immunoreactivity as well as the behavioral profile. Further, at $48 \mathrm{~h}$, when there was a considerable reduction in anxietylike behavior, the CART fiber population was drastically reduced. We presume that at this time point, reduced secretion of CART in the CeA contributes to reduced anxiety-like behavior as compared to that at $24 \mathrm{~h}$, allowing the animal to resume normal behavior. Indeed, at $72 \mathrm{~h}$, when the population of the fibers was similar to that of the pair-fed controls, anxiety-like behavior was markedly reduced and not significantly different from the pair-fed animals. While the site of origin of the CART fibers in the $\mathrm{CeA}$ is not known, we suspect that these may originate from the hypothalamic ARC as $\alpha$-melanocyte stimulating hormone $(\alpha-\mathrm{MSH})$-containing cells of the ARC are known to coproduce CART (Barsh and Schwartz, 2002; Wittmann et al, 2005) and project to amygdala (Eskay et al, 1979; O'Donohue et al, 1979).

It is of interest that CART and $\alpha$-MSH show a considerable degree of overlap in their distribution and physiological properties. Both peptides are anorectic (Tian et al, 2004) and implicated in the regulation of anxiety-like behavior, depression, and stress like conditions (Kuhar et al, 2002; Chaki et al, 2003; Kokare et al, 2005; Goyal et al, 2006; Stanek, 2006). In addition, $\alpha$-MSH has anxiogenic properties (Kokare et al, 2005) and increases in association with ethanol withdrawal-induced anxiety-like behavior (Kokare et al, 2006). Furthermore, administration of antibodies against $\alpha$-MSH enhances the anxiolytic effect of ethanol (Kokare et al, 2006). Taken together, the data suggest that $\alpha-\mathrm{MSH}$ and CART may jointly influence or potentiate the anxiogenic behavior through actions in the amygdala.

In addition to CeA, the BNSTl and AcbSh also showed the presence of CART-immunoreactive elements (Koylu et al, $1997,1998)$ and are known to play a key role in drug abuse and dependence (Koob, 1992; Koob and Le Moal, 1997; Olive et al, 2002; Funk et al, 2006). CART-immunoreactive neurons have been reported in the AcbSh of rats (Salinas et al, 2006), and numerous studies have demonstrated an involvement of these areas in physiological responses associated with anxiety-like behavior (LeDoux et al, 1988; Walker and Davis, 1997). Nevertheless, administration of CART into the BNSTl and AcbSh at the same doses used for intra-CeA injection, did not alter the anxiety-like behavior assessed by the social interaction test. The administration of CART antibody in these brain sites did not influence the time spent in social interaction at $24 \mathrm{~h}$ following ethanol withdrawal, and the CART immunoreactivity profile following ethanol withdrawal at $0,24,48$, and $72 \mathrm{~h}$ time points remained unchanged. Taken together, the data indicate that the CeA, and not BNSTl and AcbSh, is the primary locus of action of CART to produce anxiety-like behavior following ethanol withdrawal. Funk et al (2006) have similarly observed that the role of corticotropin releasing hormone to enhance ethanol self-administration in ethanol-withdrawn and -dependent rats is mediated in the CeA whereas BNSTl and AcbSh may not be involved.

CART has been extensively implicated in drug reward, reinforcement, and addiction (Kuhar et al, 2002; Salinas et al, 2006; Vicentic and Jones, 2007) and therefore, the possibility exists that CART may be closely linked with ethanol pharmacology. The present study suggests a possible correlation between ethanol withdrawal-generated anxiety-like behavior and the CART-containing system in the CeA of the rat. We suggest that chronic ethanol exposure may cause functional adaptations in the CART 
neuronal circuitries in the CeA, heightening expression following ethanol withdrawal and precipitating anxiety-like symptoms.

\section{ACKNOWLEDGEMENTS}

Supported by the Grant from the Department of Science and Technology (SP/SO/C-39/99), Govt of India, New Delhi, India.

\section{DISCLOSURE/CONFLICT OF INTEREST}

The author(s) (MPD, PSS, DMK, RML, JJC, NS) declare that, except for income received from their primary employer, no financial support or compensation has been received from any individual or corporate entity over the past three years for research or professional service and there are no personal financial holdings that could be perceived as constituting a potential conflict of interest. The author, LT is employed by and has equity interest with Novo Nordisk A/S, Denmark.

\section{REFERENCES}

Adolphs R, Tranel D, Damasio H, Damasio A (1994). Impaired recognition of emotion in facial expressions following bilateral damage to the human amygdala. Nature 372: 669-672.

Asakawa A, Inui A, Yuzuriha H, Nagata T, Kaga T, Ueno N et al (2001). Cocaine-amphetamine-regulated transcript influences energy metabolism, anxiety and gastric emptying in mice. Horm Metab Res 33: 554-558.

Bannon AW, Seda J, Carmouche M, Francis JM, Jarosinski MA, Douglass J (2001). Multiple behavioral effects of cocaine- and amphetamine-regulated transcript (CART) peptides in mice: CART 42-89 and CART 49-89 differ in potency and activity. J Pharmacol Exp Ther 299: 1021-1026.

Barsh GS, Schwartz MW (2002). Genetic approaches to studying energy balance: perception and integration. Nat Rev Genet 3: 589-600.

Chaki S, Kawashima N, Suzuki Y, Shimazaki T, Okuyama S (2003). Cocaine- and amphetamine-regulated transcript peptide produces anxiety-like behavior in rodents. Eur J Pharmacol 464: 49-54.

Couceyro PR, Koylu EO, Kuhar MJ (1997). Further studies on the anatomical distribution of CART by in situ hybridisation. J Chem Neuroanat 12: 229-241.

Criado JR, Morales M (2000). Acute ethanol induction of c-Fos immunoreactivity in pre-pro-enkephalin expressing neurons of the central nucleus of the amygdala. Brain Res 861: 173-177.

Douglass J, McKinzie AA, Couceyro P (1995). PCR differential display identifies a rat brain mRNA that is transcriptionally regulated by cocaine and amphetamine. J Neurosci 15: 2471-2481.

Elias CF, Lee C, Kelly J, Aschkenasi C, Ahima RS, Couceyro PR et al (1998). Leptin activates hypothalamic CART neurons projecting to the spinal cord. Neuron 21: 1375-1385.

Eskay RL, Giraud P, Oliver C, Brown-Stein MJ (1979). Distribution of alpha-melanocyte-stimulating hormone in the rat brain: evidence that alpha-MSH-containing cells in the arcuate region send projections to extra-hypothalamic areas. Brain Res 178: 55-67.

File SE, Hyde JR (1978). Can social interaction be used to measure anxiety? Br J Pharmacol 62: 19-24.

Funk CK, O' Dell LE, Crawford EF, Koob GF (2006). Corticotropinreleasing factor within the central nucleus of the amygdala mediates enhanced ethanol self-administration in withdrawn, ethanol-dependent rats. J Neurosci 26: 11324-11332.

Gautvik KM, de Lecea L, Gautvik VT, Danielson PE, Tranque P, Dopazo A et al (1996). Overview of the most prevalent hypothalamus-specific mRNAs, as identified by directional tag PCR subtraction. Proc Natl Acad Sci USA 93: 8733-8738.

Gonzalez LE, File SE, Overstreet DH (1998). Selectively bred lines of rats differ in social interaction and hippocampal $5-\mathrm{HT}_{1 \mathrm{~A}}$ receptor function: a link between anxiety and depression? Pharmacol Biochem Behav 59: 787-792.

Goyal SN, Kokare DM, Chopde CT, Subhedar NK (2006). Alphamelanocyte stimulating hormone antagonizes antidepressantlike effect of neuropeptide Y in Porsolt's test in rats. Pharmacol Biochem Behav 85: 369-377.

Jung SK, Hong MS, Suh GJ, Jin SY, Lee HJ, Kim BS et al (2004). Association between polymorphism in intron 1 of cocaine- and amphetamine-regulated transcript gene with alcoholism, but not with bipolar disorder and schizophrenia in Korean population. Neurosci Lett 365: 54-57.

Kask A, Schioth HB, Mutulis F, Wikberg JE, Rago L (2000). Anorexigenic cocaine- and amphetamine-regulated transcript peptide intensifies fear reactions in rats. Brain Res 857: 283-285.

Knapp DJ, Overstreet DH, Moy SS, Breese GR (2004). SB242084, flumazenil, and CRA1000 block ethanol withdrawal-induced anxiety in rats. Alcohol 32: 101-111.

Kokare DM, Chopde CT, Subhedar NK (2006). Participation of $\alpha$-melanocyte stimulating hormone in ethanol-induced anxiolysis and withdrawal anxiety in rats. Neuropharmacology 51: 536-545.

Kokare DM, Dandekar MP, Chopde CT, Subhedar N (2005). Interaction between neuropeptide $\mathrm{Y}$ and alpha-melanocyte stimulating hormone in amygdala regulates anxiety in rats. Brain Res 1043: 107-114.

Koob GF (1992). Drugs of abuse: anatomy, pharmacology and function of reward pathways. Trends Pharmacol Sci 13: 177-184.

Koob GF (2003a). Alcoholism: allostasis and beyond. Alcohol Clin Exp Res 27: 232-243.

Koob GF (2003b). Neuroadaptive mechanisms of addiction: studies on the extended amygdala. Eur Neuropsychopharmacol 13: $442-452$.

Koob GF, Le Moal M (1997). Drug abuse: hedonic homeostatic dysregulation. Science 278: 52-58.

Koylu EO, Couceyro PR, Lambert PD, Kuhar MJ (1998). Cocaineand amphetamine-regulated transcript peptide immunohistochemical localization in the rat brain. J Comp Neurol 391: 115-132.

Koylu EO, Couceyro PR, Lambert PD, Ling NC, DeSouza EB, Kuhar MJ (1997). Immunohistochemical localization of novel CART peptides in rat hypothalamus, pituitary and adrenal gland. J Neuroendocrinol 9: 823-833.

Kristensen P, Judge ME, Thim L, Ribel U, Christjansen KN, Wulff BS et al (1998). Hypothalamic CART is a new anorectic peptide regulated by leptin. Nature 393: 72-76.

Kuhar MJ, Adams S, Dominguez G, Jaworski J, Balkan B (2002). CART peptides. Neuropeptides 36: 1-8.

Kuhar MJ, Dall Vechia SE (1999). CART peptides: novel addiction and feeding-related neuropeptides. Trends Neurosci 22: 316-320.

Kuhar MJ, Yoho LL (1999). CART peptide analysis by Western blotting. Synapse 33: 163-171.

LeDoux JE, Iwata J, Cicchetti P, Reis DJ (1988). Different projections of the central amygdaloid nucleus mediate autonomic and behavioral correlates of conditioned fear. $J$ Neurosci 8: 2517-2529.

Merlo Pich E, Lorang M, Yeganeh M, Rodriguez de Fonseca F, Raber J, Koob GF et al (1995). Increase of extracellular corticotropin-releasing factor-like immunoreactivity levels in the amygdala of awake rats during restraint stress and ethanol withdrawal as measured by microdialysis. J Neurosci 15: 5439-5447. 
Moller C, Wiklund L, Sommer W, Thorsell A, Heilig M (1997). Decreased experimental anxiety and voluntary ethanol consumption in rats following central but not basolateral amygdala lesions. Brain Res 760: 94-101.

O’Donohue TL, Miller RL, Jacobowitz DM (1979). Identification, characterization and stereotaxic mapping of intraneuronal alpha-melanocyte stimulating hormone-like immunoreactive peptides in discrete regions of the rat brain. Brain Res 176: 101-123.

Olive MF, Koenig HN, Nannini MA, Hodge CW (2002). Elevated extracellular CRF levels in the bed nucleus of the stria terminalis during ethanol withdrawal and reduction by subsequent ethanol intake. Pharmacol Biochem Behav 72: 213-220.

Pandey SC (2004). The gene transcription factor cyclic AMPresponsive element binding (CREB) protein: role in positive and negative affective states of alcohol addiction. Pharmacol Ther 104: $47-58$.

Pandey SC, Roy A, Zhang H (2003). The decreased phosphorylation of cyclic adenosine monophosphate (cAMP) response element binding (CREB) protein in the central amygdala acts as a molecular substrate for anxiety related to ethanol withdrawal in rats. Alcohol Clin Exp Res 27: 396-409.

Pandey SC, Zhang D, Mittal N, Nayyar D (1999). Potential role of the gene transcription factor cyclic AMP-responsive element binding protein in ethanol withdrawal-related anxiety. J Pharmacol Exp Ther 288: 866-878.

Paxinos G, Watson C (1998). The Rat Brain in Stereotaxic Coordinates. Academic Press: London.

Sakharkar AJ, Singru PS, Sarkar K, Subhedar NK (2005). Neuropeptide $\mathrm{Y}$ in the forebrain of the adult male cichlid fish Oreochromis mossambicus: distribution, effects of castration and testosterone replacement. J Comp Neurol 489: 148-165.

Salinas A, Wilde JD, Maldve RE (2006). Ethanol enhancement of cocaine- and amphetamine-regulated transcript mRNA and peptide expression in the nucleus accumbens. J Neurochem 97: 408-415.

Scruggs P, Dun SL, Dun NJ (2003). Cocaine- and amphetamineregulated transcript peptide attenuates phenylephrine-induced bradycardia in anesthetized rats. Am J Physiol Regul Integr Comp Physiol 285: R1496-R1503.

Singru PS, Sanchez E, Fekete C, Lechan RM (2007). Importance of melanocortin signaling in refeeding-induced neuronal activation and satiety. Endocrinology 148: 638-646.

Smith SM, Vaughan JM, Donaldson CJ, Rivier J, Li C, Chen A et al (2004). Cocaine- and amphetamine-regulated transcript activates the hypothalamic-pituitary-adrenal axis through a corticotropinreleasing factor receptor-dependent mechanism. Endocrinology 145: 5202-5209.

Smith Y, Kieval J, Couceyro PR, Kuhar MJ (1999). CART peptideimmunoreactive neurones in the nucleus accumbens in monkeys: ultrastructural analysis, colocalization studies, and synaptic interactions with dopaminergic afferents. J Comp Neurol 407: 491-511.

Stanek LM (2006). Cocaine- and amphetamine-related transcript (CART) and anxiety. Peptides 27: 2005-2011.

Thim L, Kristensen P, Nielsen PF, Wulff BS, Clausen JT (1999). Tissue-specific processing of cocaine- and amphetamine-regulated transcript peptides in the rat. Proc Natl Acad Sci USA 96: 2722-2727.

Thim L, Nielsen PF, Judge ME, Andersen AS, Diers I, Egel-Mitani $M$ et al (1998). Purification and characterization of a new hypothalamic satiety peptide, cocaine and amphetamine regulated transcript (CART), produced in yeast. FEBS Lett 428: 263-268.

Tian DR, Li XD, Shi YS, Wan Y, Wang XM, Chang JK et al (2004). Changes of hypothalamic alpha-MSH and CART peptide expression in diet-induced obese rats. Peptides 25: 2147-2153.

Vicentic A, Jones DC (2007). The CART (cocaine- and amphetamine-regulated transcript) system in appetite and drug addiction. J Pharmacol Exp Ther 320: 499-506.

Vrang N, Larsen PJ, Clausen JT, Kristensen P (1999). Neurochemical characterization of hypothalamic cocaine-amphetamineregulated transcript neurons. J Neurosci 19: RC5.

Walker DL, Davis M (1997). Double dissociation between the involvement of the bed nucleus of the stria terminalis and the central nucleus of the amygdala in startle increases produced by conditioned versus unconditioned fear. J Neurosci 17: 9375-9383.

Wittmann G, Liposits Z, Lechan RM, Fekete C (2005). Origin of cocaine- and amphetamine-regulated transcript-containing axons innervating hypophysiotropic corticotropin-releasing hormone-synthesizing neurons in the rat. Endocrinology 146: 2985-2991.

Yermolaieva O, Chen J, Couceyro PR, Hoshi T (2001). Cocaineand amphetamine-regulated transcript peptide modulation of voltage gated $\mathrm{Ca}^{2+}$ signaling in hippocampal neurons. J Neurosci 21: 7474-7480.

Zhang H, Pandey SC (2003). Effects of PKA modulation on the expression of neuropeptide $\mathrm{Y}$ in rat amygdaloid structures during ethanol withdrawal. Peptides 24: 1397-1402.

Supplementary Information accompanies the paper on the Neuropsychopharmacology website (http://www.nature.com/npp) 